\title{
Risk Factors and Treatment at Recurrent Stroke Onset: Results from the Recurrent Stroke Quality and Epidemiology (RESQUE) Study
}

\author{
T. Leoo ${ }^{a} \quad$ A. Lindgren ${ }^{b} \quad$ J. Petersson ${ }^{c} \quad$ M. von Arbin ${ }^{d}$

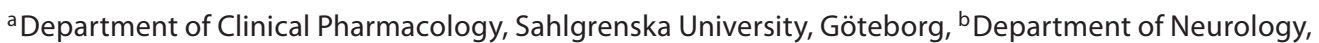 \\ Lund University Hospital, Lund, ' Department of Neurology, Malmö University Hospital, Malmö, and \\ ${ }^{\mathrm{d}}$ Department of Clinical Sciences, Karolinska Institutet, Danderyds Hospital, Stockholm, Sweden
}

\section{Key Words}

Ischemic stroke $\cdot$ Recurrent stroke $\cdot$ Cardiovascular risk factors $\cdot$ Intracerebral hemorrhage

\begin{abstract}
Background: Much effort has been made to study first-ever stroke patients. However, recurrent stroke has not been investigated as extensively. It is unclear which risk factors dominate, and whether adequate secondary prevention has been provided to patients who suffer from recurrent stroke. Also, the different types of recurrent stroke need further evaluation. Methods: The study included patients with recurrent stroke admitted to twenty-three Swedish stroke centers. The type of previous and recurrent stroke was determined, as well as evaluation (when applicable) of recurrent ischemic stroke according to the TOAST classification. Presence of vascular risk factors was registered and compared to the type of stroke. Also assessed was ongoing secondary prevention treatment at recurrent stroke onset. Results: $A$ total of 889 patients with recurrent stroke (mean age 77 ) were included in the study. Of these, 805 (91\%) had ischemic stroke, 78 (9\%) had intracerebral hemorrhage and $6(<1 \%)$ stroke of unknown origin. The most frequent vascular risk factors were hypertension (75\%) and hyperlipidemia (56\%). Among the 889 patients, $29 \%$ had atrial fibrillation. Of the patients in the ischemic group with cardiac embolism, only
\end{abstract}

\section{KARGER}

Fax +41613061234

E-Mail karger@karger.ch

www.karger.com (c) 2008 S. Karger AG, Basel

$1015-9770 / 08 / 0253-0254 \$ 24.50 / 0$

Accessible online at:

www.karger.com/ced
$21 \%$ were on anticoagulation treatment. The majority of the patients (75\%) had their most recent previous stroke $>12$ months before admission. Conclusions: Few patients had a recurrent stroke shortly after the previous stroke in this study. This indicates that it is meaningful to prevent a second event with an adequate long-term treatment strategy for secondary prevention after first-ever stroke. There also seems to be a clear potential for improving secondary prevention after stroke.

Copyright $\odot 2008$ S. Karger AG, Basel

\section{Introduction}

Stroke is one of the most costly diseases in the community both from a humanitarian and economic point of view [1]. To prevent recurrent stroke events, the standard strategy today aims at reducing the risk factors involved in atherosclerosis, heart disease and metabolic disorders. This includes blood pressure treatment, lipid-lowering agents and platelet inhibitors. A better understanding of the relative importance of the risk factors could lead to a better secondary prevention and thus limit the future stroke burden in the increasingly elderly population.

The RESQUE investigators are listed in the appendix.
Magnus von Arbin, MD, $\mathrm{PhD}$

Department of Clinical Sciences

Karolinska Institutet, Danderyds Hospital

SE-18288 Stockholm (Sweden)

Tel. +46 86556 450, Fax +46 86226 810, E-Mail magnus.vonarbin@ds.se 
Several studies have determined the incidence and outcome of ischemic stroke patients with respect to different TOAST subtypes. In a first-ever stroke population, the age-standardized incidence rates for a European population (per 100,000/year) regarding TOAST subtypes was 30.2 for cardioembolism, 25.8 for small artery occlusion and 15.3 for large artery atherosclerosis [2]. Two years after onset, the age-adjusted patient population in the small artery occlusion subgroup was 3 times more likely to be alive than those with cardioembolism, and ischemic stroke subtype according to TOAST was also a significant predictor of long-term survival.

Despite all efforts to reduce the risk of future stroke, approximately $25 \%$ of the patients in a stroke unit are individuals with a recurrent event [3]. The risk for a recurrent stroke has been reported to be about $4 \%$ in the first month and about $12 \%$ in the first year after stroke onset with the first period after the event being the most vulnerable [4]. Recurrent stroke events during the 1st year are in a majority of the cases attributable to atherosclerosis of the large arteries [5]. During the following years, cardiovascular risk factors and concomitant diseases such as diabetes mellitus, atrial fibrillation, hypertension and hypercholesterolemia seem to be the most important risk factors [6-8]. After the 1st year, the annual frequency of recurrent stroke has been reported to be 4-5\% [9].

Guidelines have been published to describe how to prevent recurrent stroke $[10,11]$, but, compared with data on risk factor handling after the initial stroke, information on risk factors for recurrent stroke is limited. The reported time to stroke recurrence also seems to vary between different studies. In that perspective, the Recurrent Stroke Quality and Epidemiology (RESQUE) study was planned to give additional understanding of the recurrent stroke population.

\section{Patients and Methods}

\section{Patients}

Patients included had to be 18 years or older. A written informed consent had to be signed by the patient, a relative or a health representative other than the investigator. The study included consecutive patients with recurrent ischemic or hemorrhagic stroke admitted to a dedicated stroke unit in eight University hospitals and 15 other hospitals. The patients had a history of ischemic, hemorrhagic or undetermined stroke before the qualifying recurrent stroke. No time limit since the previous stroke was set. The decision that a repeated event had occurred was at the discretion of the investigator, and the patients were handled and treated according to routine practice. Patients with subarachnoidal bleeding were excluded from the study. The study was approved by the ethical committee at the Karolinska Institute in Stockholm.
Table 1. Definitions of history/risk factors

\section{History of cardiovascular diseases}

Ischemic Angina pectoris, myocardial infarction or previheart disease ous percutaneous transluminal cardiac angioplasty or cardiac angioplasty bypass graft

Intermittent Diagnosis of peripheral arterial disease or sympclaudication tomatic intermittent claudication with ankle brachial index $<0.9$

\begin{tabular}{l}
$\begin{array}{l}\text { Carotid } \\
\text { surgery }\end{array}$ \\
\hline
\end{tabular}

\section{Current risk factors}

Carotid artery Carotid artery stenosis with a lumen diameter restenosis duction of $50 \%$ or more

Hyper- Medically treated hypertension on arrival to the tension hospital or detected persistent hypertension (>140/90) during observation period

\begin{tabular}{ll}
\hline $\begin{array}{l}\text { Angina } \\
\text { pectoris }\end{array}$ & Symptomatic or treated angina pectoris \\
\hline $\begin{array}{l}\text { Diabetes } \\
\text { mellitus }\end{array}$ & $\begin{array}{l}\text { Treated or detected raised plasma blood glucose } \\
\text { (P-glucose } \geq 7 \text { mM or B-glucose } \geq 6.1 \mathrm{mM} \text {, diet or } \\
\text { medical antidiabetic treatment) }\end{array}$
\end{tabular}

Hyper- Treated or detected hyperlipidemia (S-cholesterlipidemia ol $\geq 5 \mathrm{~mm}$ and/or $\mathrm{LDL} \geq 3 \mathrm{mM}$, diet or medical antihyperlipidemia treatment)

\begin{tabular}{ll}
\hline $\begin{array}{l}\text { Atrial } \\
\text { fibrillation }\end{array}$ & $\begin{array}{l}\text { Diagnosed paroxysmal atrial fibrillation, atrial fi- } \\
\text { brillation on admission to the hospital or during } \\
\text { the observation period }\end{array}$ \\
\hline $\begin{array}{l}\text { Cardiac } \\
\text { failure }\end{array}$ & $\begin{array}{l}\text { Clinical history of cardiac failure or echocardiog- } \\
\text { raphy with ejection fraction }<45 \%\end{array}$ \\
\hline $\begin{array}{l}\text { Cardiac } \\
\text { vitium }\end{array}$ & $\begin{array}{l}\text { Mitral or aortic stenosis/insufficiency diagnosed } \\
\text { by echocardiography }\end{array}$ \\
\hline
\end{tabular}

\section{Mechanical}

heart valve

\begin{tabular}{ll}
\hline Smoking & Daily use of cigarettes or pipe \\
\hline Obesity & Body mass index of more than 30 \\
\hline $\begin{array}{l}\text { High alcohol } \\
\text { consumption }\end{array}$ & $\begin{array}{l}\text { Use of more than } 8 \mathrm{cl} \text { of alcohol daily or } 56 \mathrm{cl} / \\
\text { week }\end{array}$ \\
\hline
\end{tabular}

\section{Methods}

The primary objective of RESQUE was to investigate established vascular risk factors and their association with the type of recurrent ischemic stroke, classified according to TOAST subtypes [12], in a large representative population of patients with recurrent stroke admitted to a stroke unit. Information about previous and current risk factors (definitions given in table 1) was collected from the clinical examination, patient history and routine laboratory tests. Ongoing medical treatment at the onset of recurrent stroke was registered and patients with recurrent hem- 
orrhagic stroke were also assessed. Time since last previous stroke was grouped into: within 1 month, 1-3 months, 4-12 months and more than 12 months. The proportion of patients evaluated with $\mathrm{CT} / \mathrm{MRT}$ was used as a quality marker.

\section{Statistical Methods}

Standard descriptive statistics were used to describe the variables collected, and summary measures, e.g. means and/or medians, standard deviations, minimum and maximum and percentiles, were calculated. Categorical variables were summarized as counts and percentages.

Associations between the TOAST subtypes and known dichotomous risk factors were evaluated with $\chi^{2}$ tests. The nonparametric alternative, Fisher's exact test, was used for sparse crosstables with expected counts below 5 in one or more of the cells.

All tests were two sided and the significance level was set to $5 \%$. The $\mathrm{p}$ values presented have not been adjusted for multiple testing. The statistical package Stata 9.0 (StataCorp, College Station, Tex., USA) was used for the statistical analysis.

\section{Results}

Between November 21, 2004, and July 11, 2006, 889 patients with recurrent stroke (mean age 77, range 40-98 years, 504 males) were included in the study. Among these, 805 (91\%) had ischemic stroke, 78 (9\%) had intracerebral hemorrhage and $6(<1 \%)$ undetermined cause of the stroke. CT examination was performed in $99.6 \%$ of the patients, MRT in 6\%, carotid artery duplex in 34\% and echocardiography in $14 \%$. Of the 889 included patients, 56 (6\%) died during their stay at the stroke unit.

The most frequent risk factor (table 2) was hypertension (75\%) followed by hyperlipidemia (56\%). Among the 889 patients, $37 \%$ had ischemic heart disease, $29 \%$ atrial fibrillation and $24 \%$ diabetes mellitus. Thirteen percent were current smokers and $11 \%$ were classified as obese. Overall, patients in the ischemic group had more risk factors compared to the hemorrhagic group, with $51 \%$ of the patients in the ischemic group having three or more risk factors compared to $33 \%$ in the hemorrhagic group $(\mathrm{OR}=2.10,95 \% \mathrm{CI}: 1.28-3.44, \mathrm{p}=0.003)$.

The proportions of patients with some major risk factors in relation to stroke type/subtype are shown in table 3. In the ischemic group, there were significantly more patients with atrial fibrillation and hyperlipidemia than in the hemorrhagic group $(\mathrm{OR}=1.88,95 \% \mathrm{CI}$ : $1.03-3.42$, $\mathrm{p}=0.04$, and $\mathrm{OR}=1.78,95 \% \mathrm{CI}: 1.03-3.10, \mathrm{p}=0.04$, respectively). Divided into TOAST subtypes, the cardiac emboli group was older than the rest of the ischemic stroke group (median age 82 vs. 78 years, $p=0.001$ ). There were no statistically significant differences between hemorrhagic and ischemic stroke patients, or within the dif-
Table 2. History of known risk factors at recurrent stroke onset (all patients, $\mathrm{n}=889$ ), age not included

\begin{tabular}{lrc}
\hline Risk factor $^{1}$ & $\mathrm{n}$ & $\%$ \\
\hline Previous ischemic stroke & 802 & $90^{1}$ \\
Previous hemorrhagic stroke & 94 & $11^{1}$ \\
Previous stroke of unknown origin & 10 & $1^{1}$ \\
Hypertension & 658 & 75 \\
Hyperlipidemia & 388 & 56 \\
Male & 504 & 57 \\
Ischemic heart disease & 317 & 37 \\
Atrial fibrillation & 253 & 29 \\
Diabetes mellitus & 212 & 24 \\
Angina pectoris & 198 & 23 \\
Carotid artery stenosis & 92 & 16 \\
Congestive heart failure & 114 & 13 \\
Smoking & 114 & 13 \\
Obesity & 98 & 11 \\
Cardiac vitium & 37 & 4.3 \\
Intermittent claudication & 34 & 4.0 \\
High alcohol consumption & 30 & 3.6 \\
Carotid surgery & 28 & 3.2 \\
Mechanical heart valve & 8 & 0.9
\end{tabular}

${ }^{1}$ More than one previous stroke type was accepted, thus the sum does not equal $100 \%$.

ferent TOAST subtypes in the ischemic group, regarding occurrence of hypertension, diabetes or proportion of smokers.

\section{Recurrent Stroke Caused by Ischemic Stroke}

According to the TOAST subtypes of the ischemic stroke group, 'small vessel disease' ( $\mathrm{n}=275 ; 34 \%)$ was the most common, followed by 'large artery disease' ( $n=213$; $26 \%)$, 'cardiac emboli' ( $\mathrm{n}=180 ; 22 \%)$, 'undetermined' (119; 15\%) and 'other' (18; 2\%). No differences were observed in TOAST subtypes in relation to time since previous stroke. The majority of the patients (75\%) had their previous stroke $>12$ months before the admission, whereas $1 \%$ had their previous stroke $<1$ month, $5 \%$ between 1-3 months and 19\% 4-12 months before the recurrent event.

The ongoing treatment at the recurrent stroke onset is described in table 4 . In the ischemic stroke population, the majority of the patients had antiplatelet treatment (79\%) when arriving at the hospital. Seventy-two percent were treated with an antihypertensive medication, $40 \%$ with a lipid-lowering agent and $11 \%$ with anticoagulation. When ongoing treatment at onset was studied regarding different TOAST subtypes, antiplatelet, antico- 
Table 3. Risk factors at recurrent stroke onset in relation to TOAST subtypes (all patients)

\begin{tabular}{lllcrrr}
\hline & $\begin{array}{l}\text { Median } \\
\text { age, years }\end{array}$ & $\begin{array}{l}\text { Hyper- } \\
\text { tension }\end{array}$ & Diabetes & $\begin{array}{l}\text { Atrial } \\
\text { fibrillation }\end{array}$ & $\begin{array}{l}\text { Hyper- } \\
\text { lipidemia }\end{array}$ & $\begin{array}{l}\text { Current } \\
\text { smokers }\end{array}$ \\
\hline Hemorrhagic stroke, $\mathrm{n}=78$ & 78 & $61(78)$ & $16(21)$ & $14(18)$ & $24(43)$ & $7(9)$ \\
All ischemic, $\mathrm{n}=805$ & 79 & $594(74)$ & $196(24)$ & $236(29)^{*}$ & $364(57)^{* *}$ & $107(14)$ \\
$\quad$ Large vessel, $\mathrm{n}=213$ & 77 & $164(78)$ & $57(27)$ & $25(12)$ & $97(57)$ & $30(15)$ \\
Cardiac emboli, $\mathrm{n}=180$ & $82^{+}$ & $132(74)$ & $36(20)$ & $154(86)^{++}$ & $66(49)$ & $18(10)$ \\
Small vessel, $\mathrm{n}=275$ & 76 & $203(74)$ & $68(25)$ & $29(11)$ & $132(59)$ & $40(15)$ \\
Other, $\mathrm{n}=18$ & 78 & $14(78)$ & $1(6)$ & $0(0)$ & $8(53)$ & $5(29)$ \\
Undetermined, $\mathrm{n}=119$ & 79 & $81(70)$ & $34(29)$ & $28(24)$ & $61(67)$ & $14(13)$ \\
\hline
\end{tabular}

Figures in parentheses indicate percentages. Due to missing values, the denominators used to calculate the percentages are not always exactly those presented in the first column. The total numbers of missing values by risk factor are: age 0 , hypertension 7 , diabetes 1 , atrial fibrillation 5, hyperlipidemia 191 and current smokers 33 .
${ }^{*} \mathrm{p}=0.04$ vs. hemorrhagic stroke; ${ }^{* *} \mathrm{p}=0.04$ vs. hemorrhagic stroke; ${ }^{+} \mathrm{p}<0.001 \mathrm{vs}$. large vessel, small vessel, other and undetermined; ${ }^{++} \mathrm{p}<0.001$ vs. large vessel, small vessel, other and undetermined.

Table 4. Ongoing treatment at recurrent stroke onset in relation to TOAST subtypes (all patients)

\begin{tabular}{|c|c|c|c|c|}
\hline & Antiplatelet & Anticoagulation & Antihypertensive & Lipid lowering \\
\hline Hemorrhagic stroke, $\mathrm{n}=78$ & $43(55)$ & $11(14)$ & $56(72)$ & $20(26)$ \\
\hline All ischemic, $\mathrm{n}=805$ & $639(79)$ & $91(11)$ & $581(72)$ & $325(40)$ \\
\hline Large vessel, $n=213$ & $179(84)$ & $14(7)$ & $154(72)$ & $86(40)$ \\
\hline Cardiac emboli, $\mathrm{n}=180$ & $127(71)^{*}$ & $38(21)^{* *}$ & $145(81)^{+}$ & $61(34)^{++}$ \\
\hline Small vessel, $\mathrm{n}=275$ & $226(82)$ & $23(8)$ & $191(69)$ & $120(44)$ \\
\hline Other, $\mathrm{n}=18$ & $13(72)$ & $3(17)$ & $16(89)$ & $8(44)$ \\
\hline Undetermined, $\mathrm{n}=119$ & $94(79)$ & $13(11)$ & $75(63)$ & $50(42)$ \\
\hline
\end{tabular}

Figures in parentheses indicate percentages. ${ }^{*} \mathrm{p}=0.001 \mathrm{vs.}$ nonembolic (large vessel, small vessel, other and undetermined); ${ }^{* *} \mathrm{p}=0.001$ vs. nonembolic (large vessel, small vessel, other and undetermined); ${ }^{+} \mathrm{p}=0.004$ vs. nonembolic (large vessel, small vessel, other and undetermined); ${ }^{++} \mathrm{p}=0.044$ vs. nonembolic (large vessel, small vessel, other and undetermined).

Table 5. Ongoing pharmacological treatment at recurrent stroke onset in relation to risk factors (all patients)

\begin{tabular}{|c|c|c|c|c|}
\hline & Antiplatelet & Anticoagulation & Hypertensive & Lipid lowering \\
\hline Hypertension, $\mathrm{n}=658$ & $511(78)$ & $78(12)$ & $591(90)$ & $265(40)$ \\
\hline Diabetes mellitus, $\mathrm{n}=212$ & $170(80)$ & $21(10)$ & $172(81)$ & $119(56)$ \\
\hline Atrial fibrillation, $n=253$ & $169(67)$ & $67(26)$ & $202(80)$ & $76(30)$ \\
\hline Hyperlipidemia, $\mathrm{n}=388$ & $313(81)$ & $46(12)$ & $290(75)$ & $295(76)$ \\
\hline Current smokers, $\mathrm{n}=114$ & $83(73)$ & $10(9)$ & $72(63)$ & $44(39)$ \\
\hline
\end{tabular}

Figures in parentheses indicate percentages. 
agulation, hypertensive and lipid-lowering medications were equal between the TOAST subtype groups, except for the cardiac embolism group. As expected in this group, significantly more patients received anticoagulation treatment compared to the other subtype groups $(21 \%$ vs. $8 \%, \mathrm{OR}=2.89,95 \%$ CI: $1.83-4.55, \mathrm{p}<0.001)$. They were also more often treated with antihypertensive medication but less often with antiplatelet and lipid-lowering agents (table 4).

Among the hypertensive patients, 90\% were receiving antihypertensive treatment at the onset of recurrent stroke and $76 \%$ of the patients with hyperlipidemia were receiving lipid-lowering agents. Antiplatelet treatment was equally used in the different risk groups, except for atrial fibrillation patients who to a greater extent were treated with anticoagulation treatment (table 5).

\section{Recurrent Stroke Caused by Intracerebral \\ Hemorrhage}

Among the 78 patients with recurrent hemorrhagic stroke, $40 \%$ had a history of previous intracerebral hemorrhage compared to $8 \%$ in patients with recurrent ischemic stroke. Fifty-five percent had ongoing antiplatelet treatment, $14 \%$ anticoagulation, $72 \%$ antihypertensive and $26 \%$ lipid-lowering medication. The median time since the previous stroke was shorter among patients with recurrent stroke caused by hemorrhage than among patients with recurrent stroke caused by cerebral infarction (82 and 119 months, respectively), but the difference was not significant $(\mathrm{p}=0.07)$.

\section{Discussion}

Recurrent stroke is common, but the reasons why patients develop repeated strokes are not fully understood. The results in the present study infer that the patients with recurrent stroke represent a population with high risk of vascular disease and have a potential for improved secondary prophylactic treatment. Half of the patients (50\%) had three or more vascular risk factors in addition to the qualifying recurrent stroke even though patients with hemorrhagic stroke seemed to have less concomitant numbers of risk factors.

RESQUE included a total of 889 patients with recurrent stroke of whom 805 had ischemic stroke. The most frequent vascular risk factors were hypertension and hyperlipidemia. Only $21 \%$ of the patients in the ischemic group with cardiac embolism were on anticoagulation treatment and the majority of the patients (75\%) had their most recent previous stroke $>12$ months before admission. Our intention was to describe a pure recurrent stroke population. The clinics that were chosen to participate have dedicated stroke units, and the stroke knowledge among the participating investigators is perceived to have been good. The multi-center approach with clinics scattered all over Sweden, including stroke units in both smaller hospitals and university clinics, intended to represent the view on stroke management for the entire country. The study aimed to consecutively include patients with recurrent stroke. However, with regard to the inclusion rate in relation to the expected yearly stroke incidence, this does not seem to have been the case in all participating clinics. In addition, the previous stroke was retrospectively assessed which could be a potential limitation in the description of the type of and time since that stroke.

Secondary prevention after stroke usually involves antiplatelet treatment, and $79 \%$ of the patients in the ischemic group were on some kind of antiplatelet agent. It has long been known that hypertension is one of the main risk factors for stroke, and $90 \%$ of the hypertensive patients in this study were receiving antihypertensive treatment. This is a high proportion, suggesting that antihypertensive treatment is instigated in patients with stroke and it has been reported that the risk for 1st-year stroke recurrence could be reduced by $50 \%$ with proper hypertension control [13]. However, the present study cannot show whether adequate target levels for blood pressure had been achieved. As for hyperlipidemia, in total $39 \%$ of all patients in the study, corresponding to $76 \%$ of the patients with hyperlipidemia, were treated with a lipid-lowering agent when admitted to the stroke unit. Recent publications on lipid-lowering advocate a better focus on cholesterol levels $[14,15]$. Even if the stroke population in this study was older than in the referred studies, there is a need for better secondary prevention treatment in this high-risk recurrent stroke group.

In the ischemic stroke group, it was found that the TOAST subtypes did not differ in terms of major risk factors, with the exception of the expected higher proportion of patients with atrial fibrillation on anticoagulation in the cardiac embolism group.

Only $21 \%$ of the patients with cardiac embolism were on anticoagulation treatment, a group that has been shown to have a higher mortality than, e.g., the small artery occlusive group [16]. Both US and European guidelines promote anticoagulation treatment in patients with atrial fibrillation and in RESQUE $29 \%$ in the ischemic stroke group had atrial fibrillation. Even if anticoagula- 
tion treatment increases the risk for bleeding, the more severe intracranial hemorrhages seem to be few in patients receiving anticoagulation treatment after nondisabling stroke [17]. It has been concluded that age increases the risk of bleeding in patients on anticoagulation treatment but higher age also increases the risk of stroke [18]. Some stroke patients may have comorbid diseases such as epilepsy, severe dementia or gastrointestinal bleedings where anticoagulation would be of risk, but it is not believed that this could explain the observed low adherence to current guidelines. Interestingly, there were also $7-17 \%$ treated with anticoagulation in the other TOAST subtype groups. In the group with recurrent stroke due to hemorrhage, $14 \%$ were treated with anticoagulation and $10 \%$ of those anticoagulation-treated patients had a history of a previous intracerebral hemorrhage.

The distribution in TOAST subtypes among the recurrent ischemic stroke patients in this study seems to differ from previously presented results on patients with first-ever stroke. In RESQUE, both large artery disease and small vessel disease were more common (26 vs. $13 \%$ and 34 vs. 23\%) than in the first-ever stroke population presented by Kolominsky-Rabas et al. [2]. The undetermined group was substantially smaller (15 vs. 35\%) as was also the cardiac emboli group (22 vs. $27 \%$ ). Thus, it seems that the investigators in our study less often classified the patients as undetermined which has also been reported in other studies [19].

Few patients had a recurrent stroke shortly after the previous stroke in this study and the mortality was unexpectedly low. This could be due to inclusion bias; it is possible that some patients with early recurrent stroke or patients that did not survive the first days were excluded from inclusion. Since all participating centers were dedicated stroke units, it seems unlikely that this would have occurred frequently. According to previous studies, the risk for recurrent stroke is greatest during the first weeks or months after the initial event even if there could be a trend towards a smaller cumulative risk of recurrence over years $[4,20,21]$. However, even if the risk for early recurrence is relatively greater, the cumulative cardiovascular risk over time in stroke survivors may in fact be close to the numbers shown in this study, i.e. increasing after $>12$ months, mainly due to increased risk of other cardiovascular events [22]. This emphasizes the importance of long-term strategies for secondary prevention. Reasonable numbers needed to treat calculations for secondary prevention in stroke are based on the assumption that patients survive after their first stroke for several years. It has been a matter of concern whether this is true in a typically aged population. The present study indicates that recurrent stroke often occurs after a substantial period of time. This emphasizes the need for careful evaluation of this aged recurrent group with the aim to adhere to the hypertension and lipid levels advocated in current guidelines.

We used CT/MRT as a marker of diagnosis quality in this study and almost all of the included patients (99.7\%) were examined with a CT scan. This shows that substantial efforts were put into a correct diagnosis of this group of patients and this also acts as a basis for correct antiplatelet or anticoagulation treatment.

This study contributes with a characterization of stroke subtypes, risk factors and secondary prevention in patients with repeated stroke episodes. The results suggest that secondary prevention needs to be further improved in this high-risk group of patients before the recurrent stroke onset. Further studies are needed to obtain a better understanding of the differences between recurrent stroke and first-ever stroke populations, and the possibilities to prevent or delay a further vascular event.

\section{Acknowledgements}

This study was funded by sanofi-aventis and Bristol-Myers Squibb. Drs. Lindgren, Petersson and von Arbin, have received honoraria from sanofi-aventis. Dr. Leoo is a former employee of sanofi-aventis. We thank Dr. Pär-Ola Bendahl for statistical advice.

\section{Appendix}

\section{RESQUE Investigators}

The main investigator at each center is underlined.

Danderyds Hospital, Stockholm: Magnus von Arbin, AnnCharlotte Laska, Elisabeth Rooth, Rebecca Undén; Helsingborg Hospital, Helsingborg: Svend Marup-Jensen, Peter Kalén, Bo Ågren; Kalmar Hospital, Kalmar: Piotr Kobylanski, Katarzyna Janiec, Per Svensson; Karolinska University Hospital, Stockholm: Konstantinos Kostulas, Magnus Andersson, Mia von Euler, Per Holmberg, Pia Huoso, Nikolaos Kostulas, Christin Samuelsson, Magnus Thoren, Nils Gunnar Wahlgren; Kullenbergska Hospital, Katrineholm: Yngve Bjurgert, Anders Ericsson, Joanna Krasowska; Köping Hospital, Köping: Mirka Kwiatkowska, Sofia Dettmann; Ludvika Hospital, Ludvika: Peter Rindevall, JohnErik Frisell; Lund University Hospital, Lund: Arne Lindgren, Gunilla Nilsson, Gert Staaf; Malmö University Hospital, Malmö: Jesper Petersson, Mario Brizzi, Erik Danielsson, Ursula Heldmann, Maria Macek, Roland Månsson, Hélène Pessah-Rasmussen, Mats Rosvall, Pernilla Sandgren, Arkadiusz Siennicki-Lantz, Soley Thraindottir, Magnus Wahlqvist, Elisabet Zia; Mora Hospital, 
Mora: Jörg Teichert, Sven-Åke Nilsson, Mats Pauls; Mälar Hospital, Eskilstuna: Magnus Stenstam, Bo Danielsson; Norrköping Hospital, Norrköping: Petter Järemo; Ryhov Hospital, Jönköping: Owe Lannemyr; Sahlgrenska University Hospital (neuro), Göteborg: Jan-Erik Karlsson, Karin Nylén, Eva Szentgyörgyi; Sahlgrenska University Hospital (angio), Göteborg: Lena Bokemark, Torbjörn Almgren, Pia Linton-Dahlöf, Michael Fu; Skövde Hospital, Skövde: Björn Cederin, Eric Bertholds; S:t Görans Hospital,
Stockholm: Bo Höjeberg; Sunderby Hospital, Luleå: Џohan Niklasson, Dusan Jovic; Södra Älvsborg Hospital, Borås: \an Eriksson, Elke Dahland, Warwick Lillas, Jolanta Lundebergh, Georg Mertin, Maria Paaske; Umeå University Hospital, Umeå: Tage Strand; Västervik Hospital, Västervik: Torbjörn Wallén; Örebro University Hospital, Örebro: Peter Appelros, Susanne KarlssonTivenius, Margareta Samuelsson.

\section{References}

1 Taylor TN, Davis PH, Torner JC, Holmes J, Meyer JW, Jacobson MF: Lifetime cost of stroke in the United States. Stroke 1996;27: 1459-1466.

-2 Kolominsky-Rabas PL, Weber M, Gefeller O, Neundoerfer B, Heuschmann PU: Epidemiology of ischemic stroke subtypes according to TOAST criteria: incidence, recurrence, and long-term survival in ischemic stroke subtypes: a population-based study. Stroke 2001;32:2735-2740.

-3 Kolominsky-Rabas PL, SartiC, Heuschmann PU, Graf C, Siemonsen S, Neundoerfer B, Katalinic A, Lang E, Gassmann KG, von Stockert TR: A Prospective CommunityBased Study of Stroke in Germany - The Erlangen Stroke Project (ESPro). Stroke 1998; 29:2501-2506.

4 Burn J, Dennis M, Bamford J, Sandercock P, Wade D, Warlow C: Long term risk of recurrent stroke after first ever stroke. The Oxfordshire Community Stroke Project. Stroke 1994;25:333-337; erratum 1887.

$\checkmark 5$ Lovett JK, Coull AJ, Rothwell PM: Early risk of recurrence by subtype of ischemic stroke in population-based incidence studies. Neurology 2004;62:569-573.

6 Petty GW, Brown RD Jr, Whisnant JP, Sicks JD, O'Fallon WM, Wiebers DO: Survival end recurrence after first cerebral infarction: a population based study in Rochester, Minnesota, 1975 through 1989. Neurology 1998; 50:208-216.

7 Sacco RL, Shi T, Zamanillo MC, Kargman DE: Predictors of mortality and recurrence after hospitalized cerebral infarction in an urban community: the Northern Manhattan Stroke Study. Neurology 1994:44:626-634.

$>8$ Hankey GJ, Jamrozik K, Broadhurst RJ, Forbes S, Burvill PW, Anderson CS, StewartWynne EG: Five-year survival after firstever stroke and related prognostic factors in the Perth Community Stroke Study. Stroke 2000;31:2080-2086.
$\$ 9$ Hardie K, Hankey GJ, Jamrozik K, Broadhurst RJ, Anderson C: Ten-year risk of first recurrent stroke and disability after firstever stroke in the Perth Community stroke study. Stroke 2004;35:731-735.

10 Sacco RL, Adams R, Albers G, Alberts MJ, Benavente O, Furie K, Goldstein LB, Gorelick P, Halperin J, Harbaugh R, Johnston SC, Katzan I, Kelly-Hayes M, Kenton EJ, Marks M, Schwamm LH, Tomsick T; American Heart Association; American Stroke Association Council on Stroke; Council on Cardiovascular Radiology and Intervention; American Academy of Neurology. Guidelines for prevention of stroke in patients with ischemic stroke or transient ischemic attack. Stroke 2006;37:577-617.

11 The European Stroke Initiative Executive Committee and the EUSI Writing Committee: European Stroke Initiative Recommendations for Stroke Management - Update 2003. Stroke 2006;37:577-617.

- 12 Adams HP Jr, Bendixen BH, Kappelle LJ, Biller J, Love BB, Gordon DL, Marsh EE 3rd: Classification of subtype of acute ischemic stroke: definitions for use in a multicenter clinical trial. TOAST: Trial of Org 10172 in Acute Stroke Treatment. Stroke 1993;24:3541.

13 Gelin X, Xinfeng L, Wentao W, Renliang Z, Qin Y: Recurrence after ischemic stroke in Chinese patients: impact of uncontrolled modifiable risk factors. Cerebrovasc Dis 2007;23:117-120.

14 The Stroke Prevention by Aggressive Reduction in Cholesterol Levels (SPARCL) Investigators: High-dose atorvastatin after stroke or transient ischemic attack. N Engl J Med 2006;355:459-559.

15 Heart Protection Study Collaborative Group: MRC/BHF Heart Protection Study of cholesterol lowering with simvastatin in 20,536 high-risk individuals: a randomised placebo-controlled trial. Lancet 2002;360:7-22.
6 Lavados PM, Sacks C, Prina L, Escobar A, Tossi C, Araya F, Feuerhake W, Galvez M, Salinas R, Alvarez G: Incidence, case-fatality rate, and prognosis of ischaemic stroke subtypes in a predominantly Hispanic-Mestizo population in Iquique, Chile (PISCIS project): a community-based incidence study. Lancet Neurol 2007;6:140-148.

17 Saxena R, Koudstaal P: Anticoagulants versus antiplatelet therapy for preventing stroke in patients with nonrheumatic atrial fibrillation and a history of stroke or transient ischemic attack. Cochrane Database Syst Rev 2004;CD000187.

18 van Walraven C, Hart RG, Singer DE, Laupacis A, Connolly S, Petersen P, Koudstaal PJ, Chang Y, Hellemons B: Oral anticoagulants vs aspirin in nonvalvular atrial fibrillation. An individual patient metaanalysis. JAMA 2002;288:2441-2448.

19 Toso V, Carolei A, Gensini GF, Cimminiello C, Micieli G, Toni D, Zaninelli A, Bignamini AA: The Stroke in Italy and Related Impact on Outcome (SIRIO) study: design and baseline data. Neurol Sci 2006;27:S263-S267.

20 Coull AJ, Lovett JK, Rothwell PM: Oxford Vascular Study. Population based study of early risk of stroke after transient ischemic attack or minor stroke: implications for public education and organisation of services. BMJ 2004;328:326-328.

21 Hardie K, Jamrozik K, Hankey GJ, Broadhurst RJ, Anderson C: Trends in five-year survival and risk of recurrent stroke after first-ever stroke in the Perth Community Stroke Study. Cerebrovasc Dis 2005;19:179185.

22 van Wijk I, Kapelle LJ, van Gijn J, Koudstaal PJ, Franke CL, Vermeulen M, Gorter JW, Algra A, for the LiLAC study group. Long-term survival and vascular event risk after transient ischaemic attack or minor ischaemic stroke: a cohort study. Lancet 2005;365: 2098-2104. 